\title{
Kernos
}

Revue internationale et pluridisciplinaire de religion grecque antique

$4 \mid 1991$

Varia

\section{P. Cartledge \& A. Spawforth, Hellenistic and Roman Sparta}

Ioannis Loucas

\section{OpenEdition \\ Journals}

Édition électronique

URL : http://journals.openedition.org/kernos/320

DOI : $10.4000 /$ kernos.320

ISSN : 2034-7871

Éditeur

Centre international d'étude de la religion grecque antique

Édition imprimée

Date de publication : 1 janvier 1991

Pagination : 333-334

ISSN : 0776-3824

Référence électronique

Ioannis Loucas, « P. Cartledge \& A. Spawforth, Hellenistic and Roman Sparta », Kernos [En ligne], 4 I

1991, mis en ligne le 11 mars 2011, consulté le 21 septembre 2020. URL : http://

journals.openedition.org/kernos/320 ; DOI : https://doi.org/10.4000/kernos.320 
soit la traditionnelle Revue de l'Histoire des Religions ou "notre" nouvelle venue, Kernos!

L'ensemble du livre est émaillé de citations : sources antiques (textes et inscriptions) ou extraits d'articles modernes (essentiellement de tendances structuralistes) qui visent à documenter la démarche méthodologique et historiographique mise en œuvre dans ce manuel. Plusieurs "coquilles" malencontreuses devront être évitées aux prochains tirages, de façon à parfaire encore cet outil de travail agréable à lire et à assimiler, indéniablement utile à tous ceux que tentent non seulement l'étude de la religion grecque, mais aussi une meilleure compréhension de la citoyenneté antique. L. Bruit et $P$. Schmitt prouvent ici, avec une réelle vocation didactique, avec un mode d'expression dense et original, que les notions de base de ces sujets difficilement perceptibles dans toute leur altérité peuvent être rendues accessibles à un grand nombre de lecteurs. De plus, la formule choisie fait apparaitre clairement que l'histoire de la religion grecque et de son système de valeurs constitue, plus que jamais, une chaire indispensable dans les facultés universitaires abritant les sciences de l'antiquité ou, tout simplement, les sciences de l'homme.

Annie VERBANCK-PIÉRARD (Mariemont)

Paul CARTLEDGE \& Anthony SPAWFORTH, Hellenistic and Roman Sparta. A Table of Two Cities, London \& New York, Routledge, 1989, XII \& 304 p., 2 cartes (coll. "States and Cities of Ancient Greece»), 24 x $16 \mathrm{~cm}$.

Cet ouvrage, d'une importance de premier ordre pour l'historien de la Grèce hellénistique et romaine, ne présente pas moins d'intérêt pour ceux des historiens de la religion gréco-romaine qui, outre les témoignages littéraires, prennent en considération aussi les données épigraphiques et archéologiques, voire l'ensemble de la réalité sociale, économique et politique dans laquelle s'inscrivent les mythes, les croyances religieuses et les actes cultuels. Bien que dans la première partie, consacrée à la Sparte hellénistique et écrite par P. Cartledge (auteur de l'ouvrage précieux Sparte and Laconia; A Regional History 1300-362 B.C., édité aussi par Routledge en 1979), ne figure aucun chapitre relatif à la religion, une consultation de l'index en fin de volume révélera que bon nombre d'aspects religieux y sont traités : l'A. met en valeur surtout les (nouvelles) recherches et découvertes archéologiques et épigraphiques en rapport avec les fêtes et les cultes des divinités spartiates.

Les historiens de la religion grecque et romaine trouveront dans la seconde partie du livre (p. 93-211), consacrée à la Sparte romaine et écrite par A. Spawforth, un chapitre très intéressant sur le conflit du 
paganisme et du christianisme en Laconie durant l'antiquité tardive (chap. 9, p. 120-126). Avec un remarquable esprit de synthèse, l'A. présente ce conflit tel que le révèlent principalement les sources épigraphiques et archéologiques et examine la relation entre le déclin du paganisme et la disparition d'institutions sociales et politiques. Après un épilogue sur Sparte depuis la fin du monde antique jusqu'au moyen âge (p. 213), où il est très brièvement question des édifices et des églises paléo-chrétiennes de la ville, suit un premier appendice reprenant les monuments de la Sparte romaine (p. 216-225). Ils y sont classés par ordre alphabétique et accompagnés d'une référence aux sources épigraphiques et aux rapports archéologiques; parmi les diverses sortes de constructions figurent les autels, les sanctuaires, les portiques ainsi que les cimetières de la ville. L'ouvrage compte encore trois appendices (celui des magistrats, celui des fonctionnaires et celui des agonistai étrangers, p. 226-233), ainsi qu'une bibliographie qui, quoique sélective, comprend presque l'ensemble des études les plus importantes (ou les plus récentes) sur la Sparte hellénistique et romaine (p. 268-289). Un index analytique (p. 291-304) termine cet ouvrage qui nous semble réellement constituer un instrument de travail de premier ordre pour le chercheur qui se consacre non seulement à Sparte mais encore au monde gréco-romain dans son ensemble.

Ioannis LOUCAS (Athènes)

Maria DARAKI, Une religiosité sans Dieu. Essai sur les stö̈ciens d'Athènes et saint Augustin, Paris, Éditions La Découverte, 1989, 223 p., 1 vol. $13,5 \times 22 \mathrm{~cm}$. (Armillaire).

Le titre principal ne concerne assurément que le stoïcisme, et c'est à confronter cette philosophie, dans son radicalisme originel, avec la théologie de l'auteur des Confessions que s'emploie ce brillant essai. En dépit d'une inspiration religieuse et individualiste qui fait leur originalité commune, ces deux visions de l'homme n'en marquent pas moins le plus grand écart entre la pensée antique et le christianisme. D'un côté, on sacralise la nature de part en part et on en fait la source de toutes les valeurs; l'actualisation de celles-ci fait du sage un hommedieu. De l'autre, on tient la nature pour profane et pour indifférente au salut; ainsi livré à son moi, l'homme éprouve devant Dieu une totale impuissance. Dans ces expressions anciennes de l'individualisme, l'A. discerne une préfiguration de deux conceptions que la modernité, au terme d'un processus de laïcisation, engendrera successivement, celle du surhomme, celle ensuite du sujet singulier. L'ouvrage se termine par une réflexion sur l'actuel "retour du religieux" et sur sa possible transformation en des formes plus adaptées, à présent que l'action cosmique de l'homme moderne est devenue plus consciente de 